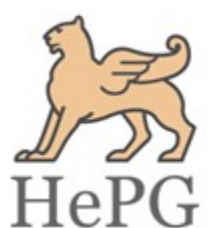

ISSN: 2348-1900

Plant Science Today

www.plantsciencetoday.online

Research Article

\title{
Plant Growth Promoting Rhizobacteria (PGPR) and Plutella xylostella (L.) (Lepidoptera: Plutellidae) interaction as a resistance inductor factor in Brassica oleracea var. capitata
}

\author{
Paula C. B. Crialesi ${ }^{1}$, Robson T. Thuler ${ }^{2}$, Fernando H. Iost Filho ${ }^{3^{*}}$, Ana Maria G. Thuler ${ }^{4}$, \\ Manoel V. F. Lemos ${ }^{1}$ and Sergio A. De Bortoli ${ }^{1}$ \\ ${ }^{1}$ College of Veterinary and Agrarian Sciences, Universidade Estadual Paulista, 14884-900, Jaboticabal, São Paulo, Brazil. \\ ${ }^{2}$ Instituto Federal de Educação, Ciência e Tecnologia do Triângulo Mineiro, 38064-790, Uberaba, Minas Gerais, Brazil. \\ ${ }^{3}$ Department of Entomology and Acarology, Universidade de São Paulo, 13418-900, Piracicaba, São Paulo, Brazil. \\ ${ }^{4}$ Universidade de Uberaba, 38055-500, Uberaba, Minas Gerais, Brazil.
}

Article history

Received: 25 April 2017

Accepted: 24 July 2017

Published: 31 July 2017

(C) Crialesi et al. (2017)

Editor

K K Sabu

Publisher

Horizon e-Publishing Group

Correspondence

Fernando H. Iost Filho

凶 fernandohiost@gmail.com

\begin{abstract}
Resistance of Plutella xylostella populations to chemical insecticides has made its management difficult, and the utilization of resistant cabbage cultivars has been shown to be a useful alternative. The objective of this study was to demonstrate the induction of cabbage plant resistance to $P$. xylostella using PGPR and injuries caused by the pest larvae as elicitors. Therefore, we evaluated the insects' responses utilizing a specific bioassay. Furthermore, this assay was used for selecting a PGPR strain that affects the insect's biology, and to examine molecular and biochemical responses of the plants influenced by the plantmicrobe-insect interaction. Among the strains used in this study, Kluyvera ascorbata showed the most relevant results by influencing biological characteristics of the insect. Thus, the following tests demonstrated that the cited strain possesses a high influence on plant metabolism when it undergoes different types of stress such as injuries caused by the pest. These findings were determined from the different responses obtained by the chemical analyses of the tested plants and from the differentiation in the genetic sequences obtained from plants inoculated with or without PGPR that were injured by the pest. The PGPR $K$. ascorbata alters the metabolism of cabbage plants, which directs a specific plant defense against $P$. xylostella.
\end{abstract}

Keywords: diamondback moth; Kluyvera ascorbata; induction resistance; HPLC; sinigrin

Crialesi P C B, Thuler R T, Iost Filho F H, Thuler A M G, Lemos M V F, De Bortoli S A. Plant Growth Promoting Rhizobacteria (PGPR) and Plutella xylostella (L.) (Lepidoptera: Plutellidae) interaction as a resistance inductor factor in Brassica oleracea var. capitata. Plant Science Today 2017;4(3):121-132. doi: 10.14719/pst.2017.4.3.305

\section{Introduction}

The diamondback moth, Plutella xylostella (L., 1758) (Lepidoptera: Plutellidae), is one of the principal pests of the Brassicaceae family and is primarily found in cabbage crops (1). The appearance of moth populations that are resistant to insecticides has made their management difficult, and as an alternative, the use of resistant cultivars has assumed an important role (2-5). Currently, genetically modified cultivars are investigated for the presence of resistance characteristics. For example, Bt plants are capable of producing proteins from the insecticidal bacteria, Bacillus thuringiensis (Bt), 
that creates resistance to attacks from specific pests. Studies with Bt plants have been conducted for half a century, and demonstrated that they are efficient biopesticides and are harmless to humans and the environment (6). However, the products based on Bt are not prominent in the insecticide market, principally due to problems with the loss of stability, the absence of translocation in the plants, the limited action spectrum and their rapid degradation due to ultra-violet light.

Induced resistance (IR) initiated by biotic and abiotic processes, is different from the use of plants modified for resistance. Furthermore, IR has lower metabolic costs, without large physiological changes in the plant, and can be highly efficient (7).

Most of the reports on IR are mediated by microorganisms related to Plant Growth Promoting Rhizobacteria (PGPR), organisms that epiphytically or endophytically colonize any part of the plant, promoting beneficial effects such as greater plant development, resistance to diseases and arthropods, as well as the adaptation to environmental stresses (8-13). In Brazil, the cabbage crop has received special attention, and promising results have been obtained in the control of diamondback moths through the use of endophytic bacteria, such as Alcaligenes piechaudii and Kluyvera ascorbata (14).

Plants are constantly damaged by insects and pathogens, which feed on and colonize their tissues. Thus, the plants create defense strategies in response to these various invaders, including physical and pre-existing chemical barriers, as well as induced defense responses that are activated before the perception of the invading organism (15-17). There are two forms of IR: systemic acquired resistance (SAR) that is normally activated by a primary infection of a physiopathic agent that induces a necrotic process in the plants (18); and induced systemic resistance (ISR), which is normally mediated by nonpathogenic rhizobacteria that colonize the roots of the plant (19).

Also, important information has been generated concerning the direct action of rhizobacteria through the production or alteration of phytohormone concentrations, nitrogen fixation, solubilization of phosphate minerals or other soil nutrients, sulfur oxidation, increased root permeability, and production of siderophores $(20,21)$. The Pseudomonas (22) and Bacillus genera have been well-studied $(23,24)$, being the last one a producer of endospores that survive for long periods in the soil and in storage (24).

Some tests were performed with PGPR isolates. Current information about the action on plants, biochemically and molecularly, is still limited. Basic information has been obtained in Arabidopsis thaliana (25), without the specific results necessary for the implementation of PGPR use in programs for pest management in different crops.

Given the worldwide importance of the brassica crop and its reduced production in tropical areas due to P. xylostella, the purpose of this study was to observe the influence of PGPRs on cabbage plants damaged by the moth. The choice of efficient PGPRs in the induction of systemic resistance is necessary to elucidate mechanical alterations and metabolic compounds involved in this process, and to detect genetic sequences related to the induced resistance response against $P$. xylostella.

\section{Materials and Methods}

\section{Seed inoculation, planting and transplanting}

Seeds of the cabbage cultivar, Brassica oleracea var. capitata hybrid 'Midori', were immersed in standardized bacterial suspensions $\left[9 \times 10^{10}\right.$ CFU (colony-forming unit)/mL + Milli-Q sterile water + Tween $\left.{ }^{\circledR} 80\right]$ for 30 minutes, by the adaptation of the method described by (26). The seeds were dried at room temperature $\left(25^{\circ} \mathrm{C}\right)$ for 12 hours. The PGPR strains used in the cabbage seed bacterization were provided by Dr. Rosa de Lima Ramos Mariano of the Phytobacteriology Laboratory of the Universidade Federal Rural de Pernambuco, PE, Brazil (UFRPE) and are described in Table 1. An untreated treatment (control) was subjected to the same procedures, but with no bacterial suspension.

The seeds were then sowed in polystyrene trays containing a commercial substrate and kept in a greenhouse. The seedlings were then transplanted to another greenhouse and were maintained using the necessary crop practices, with corrective fertilization at planting and three fertilizations at 15, 30 and 45 days after planting.

\section{Bioassay with P. xylostella larvae}

The bioassay was completed in the Laboratory of Biology and Insect Creation (LBCI) of the College of Veterinary and Agricultural Sciences at the Universidade Estadual Paulista (FCAV-UNESP) in Jaboticabal, SP, Brazil, at room temperature $\left(25 \pm 1^{\circ} \mathrm{C}\right)$, relative humidity $(70 \pm 10 \%)$ and 14 -hour photoperiod.

For the completion of the bioassay, leaves removed from plants that underwent forced injury in the greenhouses were used. The leaves were removed 60 days after the transplant, when the plants were of sufficient size to support infestation and defoliation. To injure the plants, each plant whose seeds were or were not inoculated (control) with the PGPR strains described in Table 1, were infested with 12 larvae in plastic cages $(10 \mathrm{~cm}$ in diameter by $4 \mathrm{~cm}$ in height). The median, lateral and infested leaves were removed from the plant, 
Table 1. Strains used, host plants and location of the strains.

\begin{tabular}{|c|c|c|c|}
\hline Species & Strains & Host plant (tissue) & Location \\
\hline Alcaligenes piechaudii & EN5 & B. oleracea var. capitata (leaf) & Endophytic \\
\hline Bacillus amyloliquefaciens & PEP81 & C. sativus (leaf) & Epiphytic \\
\hline B. cereus & $\mathrm{C} 210$ & Brassica oleracea var. acephala (leaf) & Epiphytic \\
\hline B. cereus & $\mathrm{C} 240$ & B. oleracea var. acephala (leaf) & Epiphytic \\
\hline B. megaterium pv. cerealis & RAB7 & Raphanus sativus (leaf) & Epiphytic \\
\hline B. pumilus & C116 & B. oleracea var. acephala (leaf) & Epiphytic \\
\hline B. subtillis & R14 & B. oleracea var. capitata (leaf) & Epiphytic \\
\hline B. thuringiensis kenyae & $\mathrm{C} 25$ & B. oleracea var. acephala (leaf) & Epiphytic \\
\hline B. thuringiensis kurstakii & HPF14 & Heliconia sp. (leaf) & Epiphytic \\
\hline Enterobacter cloacae & ENF14 & Phaseolus vulgaris (seed) & Endophytic \\
\hline E. cloacae & PEP91 & Cucumis sativus (seed) & Epiphytic \\
\hline Kluyvera ascorbata & EN4 & B. oleracea var. capitata (leaf) & Endophytic \\
\hline
\end{tabular}

and a total of five discs were removed from these leaves ( $8 \mathrm{~cm}$ in diameter) for the bioassay.

In the laboratory, the discs were added to Petri dishes $(9 \mathrm{~cm}$ in diameter) on lightly wetted filter paper, with 12 second instar larvae placed over the leaf discs for feeding, totalizing 60 individuals per treatment.

The larvae were maintained in dishes until the formation of pupae to determine larval endurance and viability. The pupae were separated into individual ELISA $^{\circledR}$ plates (Thermo Fisher, USA) until the emergence of the adults, when pupal endurance, viability, pupal weight and sex ratio were determined.

The data obtained from the bioassay were submitted to analysis of variance and were compared by the Tukey test (27). The Multivariate Cluster exploratory analysis of the data was applied (AA) (28), to select the best PGPR strain in relation to the induction of resistance against $P$. xylostella.

\section{Collection and storage of samples for biochemical and molecular tests}

For the biochemical and molecular analysis, leaves were collected from bacterized and non-bacterized plants, both of which were injured with $P$. xylostella larvae in the greenhouse. This collection coincided with the formation period of the pupae because so far, substances that would culminate in plant defense have already accumulated. The reference sample of Kluyvera ascorbata bacteria was used in the tests and selected as a function of the results obtained with the bioassay.

The samples were wrapped in aluminium foil, and the leaves that were used in the biochemical tests were stored at $-20^{\circ} \mathrm{c}$. The leaves that were used in the molecular tests were frozen in liquid nitrogen and stored at $-80^{\circ} \mathrm{C}$.

\section{Biochemical analysis by High Performance Liquid Chromatography (HPLC)}

The biochemical tests were done at the Empresa Brasileira de Pesquisa Agropecuária (EMBRAPA) in Londrina, PR, Brazil.

The leaves from the plants frozen at $-20^{\circ} \mathrm{C}$ were used for biochemical evaluation by employing the protocol utilized by (29), which was adapted by (30). Each sample was analyzed by high performance liquid chromatography (HPLC) (Shimadzu, Japan) with a CLS-ODS-C18 reverse phase column (internal diameter of $4.6 \times 250 \mathrm{~mm}$ of length).

\section{Molecular analysis}

Molecular tests were performed at the Bacterial Genetics and Applied Biotechnology Laboratory (LGBBA), at the College of Veterinary and Agricultural Sciences of the Universidade Estadual Paulista (FCAV-UNESP) in Jaboticabal, SP, Brazil.

Total RNA was isolated with TRIzol (Invitrogen, Life Technologies, USA) from the leaf tissue of cabbage plants that were injured by $P$. xylostella, whose seeds had been inoculated with $K$. ascorbata; and from plants whose seeds had not been inoculated. The total extracted RNA was treated with RNase-Free DNase (Promega, USA) and the messenger RNA (mRNA) was isolated from the total RNA with the Kit PolyATtract ${ }^{\circledR}$ mRNA Isolation System III (Promega, USA). All the procedures were completed conforming to the instructions of the manufacturer. After the extraction of genetic material, the integrity of the total RNA and the mRNA was visualized on a $1.0 \%$ agarose gel (Merck Millipore, USA), containing ethidium bromide and submitted to electrophoresis for 2 hours at $100 \mathrm{~V}$ in $1 \mathrm{X}$ TAE buffer. The gels were visualized using a UV transilluminator and photographed with a Gel Doc 2000 
device (BioRad, USA). The genetic material was quantified in a spectrophotometer (BECKMAN ${ }^{\circledR}$, model DU-640B), measuring the absorbance compared to a sample of DEPC water (Diethylpyrocarbonate - Invitrogen) at wavelengths of 260 and $280 \mathrm{~nm}$. The quantity of the RNA in the sample was estimated using the standard of one optical density unit, equal to approximately $40 \mu \mathrm{g}$ of RNA per $\mathrm{mL}$ of solution. The relationship between the readings of $260 / 280$ provides an estimate of the purity of the nucleic acid (31).

The cDNA library was constructed with $4 \mu \mathrm{g}$ of mRNA isolated from cabbage leaves in the two treatments (injured and not injured) and the "SuperScript ${ }^{\mathrm{TM}}$ Plasmid System for cDNA Synthesis and Plasmid Cloning" kit (Invitrogen, USA) was used. After synthesis of cDNA strands and the ligation of the cDNA fragments into the pCMV.SPORT6 cloning vector (provided in the kit), transformation of DH10B competent cells from Escherichia coli was performed by heat shock, according to the provided protocol (32).

The transformed clones were collected with sterile tooth picks and cultivated in 96-well microplates with $80 \mu \mathrm{L}$ of CG medium (CircleGrow B10101, MP Biomedicals, USA) and antibiotic selection (ampicillin - $50 \mathrm{mg} / \mathrm{mL}$ ) for 22 hours at $37^{\circ} \mathrm{C}$ in an incubator. After this period, $40 \%$ sterile glycerol was added to each clone $(80 \mu \mathrm{L})$ and these were stored at $-80^{\circ} \mathrm{C}$.

Extraction of the plasmid DNA was completed in 96-well plates from $20 \mu \mathrm{L}$ inoculations of each clone in $1.0 \mathrm{~mL}$ of CG medium with ampicillin in each well. The plates were incubated at $37^{\circ} \mathrm{C}$ for 22 hours, with agitation at $200 \mathrm{rpm}$. After this period, the plates were centrifuged at $3220 \mathrm{x} g$ for 5 minutes and the supernatant was discarded. The cells obtained were homogenized in $240 \mu \mathrm{L}$ of solution I ( $50 \mathrm{mM}$ Glucose $+25 \mathrm{mM}$ tris- $\mathrm{HCl}$, pH 8.0 + $10 \mathrm{mM}$ EDTA), the DNA samples were collected by centrifugation and the supernatant discarded. The precipitates were resuspended in lysis solution $(4 \mathrm{M} \mathrm{NaOH}+10 \%$ SDS) with RNAse $(10$ $\mathrm{mg} / \mathrm{mL}$ ), in a volume of $60 \mu \mathrm{L}$. The plates were agitated by inversion and incubated for 10 minutes. Neutralization solution $(60 \mu \mathrm{L})$ was added (3M $\mathrm{CH}_{3} \mathrm{COOK}-\mathrm{pH} 5.8$ ), followed by rapid centrifugation and incubation for 30 minutes at $90^{\circ} \mathrm{C}$. After this period, the plates were cooled on ice for 10 minutes. The supernatants were collected and transferred to new plates where 100 $\mu \mathrm{L}$ of absolute isopropanol was added, centrifuged for 45 minutes at $3220 \mathrm{x} g$ and the supernatant was discarded. To the remaining pellet, $200 \mu \mathrm{L}$ of ice cold $70 \%$ ethanol was added, followed by centrifugation for 5 minutes at $3220 \times \mathrm{g}$. The plates were placed in a laminar flow hood for 20 minutes to dry, and the plasmid DNA samples were resuspended in Milli-Q sterile water (30 $\mu \mathrm{l})$.

The verification of the integrity of the extracted plasmid DNA was visualized in a $0.8 \%$ agarose gel, containing ethidium bromide by electrophoresis for 2 hours at $100 \mathrm{~V}$ in $1 \mathrm{X}$ TEB buffer. The results were visualized under a UV light with photo documenter equipment and were analyzed using Quantity-one software. The plasmid DNA samples were quantified in a spectrophotometer (BECKMAN®, model DU-640B) and the concentrations were adjusted to $40 \mathrm{ng} / \mu \mathrm{L}$.

The cDNA fragments that were inserted into the vector (pCMV.SPORT 6) and cloned in E. coli were amplified by PCR using the universal oligonucleotide primers, T7 (5' TAATACGACTCACTATAGGG 3') and Sp6 (3' ATTTAGGTGACACTATAG 5'), which recognize the region of the vector where the fragments were ligated. Both amplification reactions were conducted in a volume of $20 \mu \mathrm{L}$ in 96-well PCR plates and contained the following: $160 \mathrm{ng}$ of plasmid DNA; $250 \mu \mathrm{M}$ of a dNTP solution $(10 \mathrm{mM})$; $\mathrm{MgCl}^{2}$ (1.5 Mm); $7 \mathrm{pmol}$ of each primer; $1.0 \mathrm{U}$ of the Taq DNA polymerase enzyme (Invitrogen ${ }^{\circledR}$, USA); PCR buffer solution (1X) and Milli-Q sterile water.

The amplification reactions were carried out in a thermocycler (model PTC-100, MJ Research Inc., USA), equipped with a "Hot Bonnet" circuit, utilizing an initial denaturation cycle of 5 minutes at $94^{\circ} \mathrm{C}$ and 35 cycles consisting of one denaturation cycle at $94^{\circ} \mathrm{C}$ for 30 seconds; annealing at $49^{\circ} \mathrm{C}$ for 1 minute and extension at $72^{\circ} \mathrm{C}$ for 1 minute, and at the end of the these cycles, an extra extension cycle at $72^{\circ} \mathrm{C}$ for 1 minute.

After the amplifications, the samples $(5 \mu \mathrm{L})$ were transferred to another plate with $3 \mu \mathrm{l}$ of loading buffer $(0.5 \%$ bromophenol blue in $50 \%$ glycerol). Each sample (8 $\mu \mathrm{L})$ was loaded on a 1.5\% agarose gel, containing ethidium bromide and underwent horizontal electrophoresis in a "sunrise" cube (96 channels), for 2 hours at $100 \mathrm{~V}$, in $1 X$ TEB buffer. A DNA sample was used in all the completed electrophoresis assays, with fragments of known sizes, multiples of one kilobase "1kb DNA ladder ${ }^{\circledR}$ (Fermentas), which served as an electrophoretic migration reference for verification of the fragment sizes obtained from the amplification reactions. The agarose gels were visualized under a UV light and photo documented with photo documenter equipment (Gel-Doc 2000 Bio-Rad $^{\circledR}$, USA), using Quantity-one software. The samples were quantified with a spectrophotometer (model DU-640B, Beckman ${ }^{\circledR}, \quad$ USA), the concentrations were adjusted $(100 \mathrm{ng} / \mu \mathrm{L})$ and the samples were stored at $-20^{\circ} \mathrm{C}$.

The unidirectional sequencing of each selected clone was completed using the Sequencing-Big Dye Terminator Cycle Sequencing-Ready ABI Prism Kit (Version 3) (Applied Biosystems, USA), SP6 promoter primers (3.2 pmols), plasmid DNA (100 ng), 2.5X buffer $(2.0 \mu \mathrm{L})$, Big Dye and Milli-Q q.s.p water $(10 \mu \mathrm{L})$. The reactions were completed in a thermocycler (model PTC-100, MJ Research Inc., USA), with a program consisting of 34 cycles 


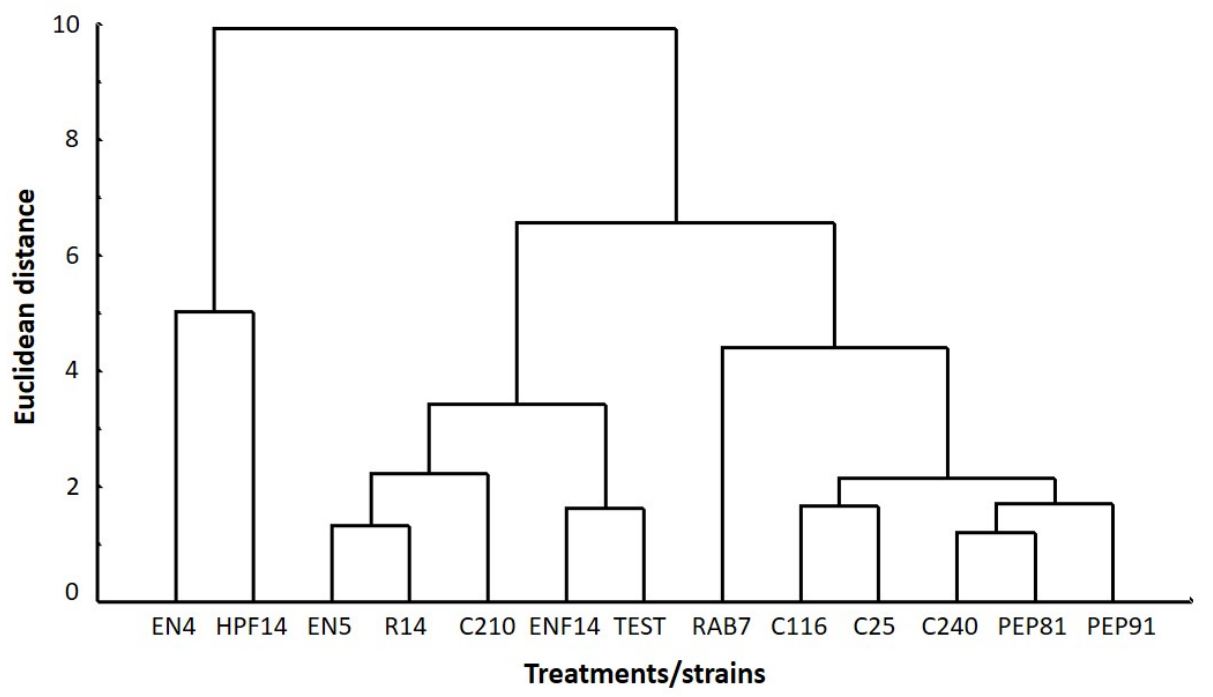

Fig. 1. Dendrogram showing the structure of groups formed by treatment with different PGPR (Plant Growth Promoting Rhizobacteria) strains and the control (TEST), in comparison to the action of treatment on second instar $P$. xylostella larvae that were maintained in the laboratory on cabbage plant leaves that were inoculated and threatened in the greenhouse.

including denaturation of the DNA strand at $96^{\circ} \mathrm{C}$ for 10 seconds, annealing of the DNA strands at $52^{\circ} \mathrm{C}$ for 5 seconds and extension at $60^{\circ} \mathrm{C}$ for 4 minutes.

After the sequencing reaction, the DNA samples were precipitated with $125 \mathrm{mM}$ EDTA (2 $\mu \mathrm{L}), 3 \mathrm{M}$ sodium acetate $(2 \mu \mathrm{L})$ and absolute ethanol $(50 \mu \mathrm{L})$, followed by rapid agitation with a vortexer and the material was incubated for 15 minutes at room temperature. The samples were centrifuged at $4^{\circ} \mathrm{C}$ for 25 minutes at $3,220 \mathrm{x} g$. The supernatant was carefully discarded and $70 \%$ ethanol $(70 \mu \mathrm{L})$ was added. Next, the mixture was centrifuged under the same conditions for 5 minutes. The supernatant was carefully discarded and the samples were placed in a dark laminar flow hood for 30 minutes to dry.

HiDi Formamide (Applied Biosystems, USA) (10 $\mu \mathrm{L}$ ) was added to each sample and they were denatured in a thermocycler at $95^{\circ} \mathrm{C}$ for 5 minutes. Next, the samples were immediately cooled on ice before sequencing in a 3100 Genetic Analyzer (Applied Biosystems, USA).

The sequences were visualized with MEGA version 4 software (33) and electropherograms were generated. These sequences were compared using BLAST "Basic Local Alignment Search Tools" (34), which is available at the National Center for Biotechnology Information (NCBI) https://blast.ncbi.nlm.nih.gov/Blast.cgi. The sequences were described based on the A. thaliana genome, which is available at http://www.arabidopsis.org/, which is a resource for information on Arabidopsis ("The Arabidopsis Information Resource” or TAIR).

\section{Results and Discussion}

\section{Bioassay with P. xylostella larvae}

The biological parameters evaluated were subjected to analysis of variance, which showed significant differences. The table containing the full analysis is not presented because the conjunct effects over the insect's biology were considered more important. Conjunct effects are explained using a multivariate analysis (see Fig. 1) that generated a grouping among the treatments. This helped selecting the most efficient strain for managing $P$. xylostella.

The insects that fed on leaves from plants treated with the EN4 strain of $K$. ascorbata generally presented low larval and pupal viability, pupal endurance, pupal weight and sex ratio, in comparison to the other treatments and the control. Duration of the larval period was elevated in comparison to the other treatments, as well as the total mortality. Larvae maintained on leaves treated with the EN4 strain had a much longer larval phase; however, they fed much less or not at all, resulting in less damage to the plants.

Although the analysis of variance and the Tukey comparisons did not reveal large differences among the treatments, the various observed effects on the different measured biological characteristics jointly, culminate in a considerable population reduction through the passage of generations.

The dendogram (Fig. 1) generated from the grouping analysis using the Statistica software, directed the choice of the EN4 strain of $K$. ascorbata because this treatment distanced itself from the control, and formed a very distinct group 


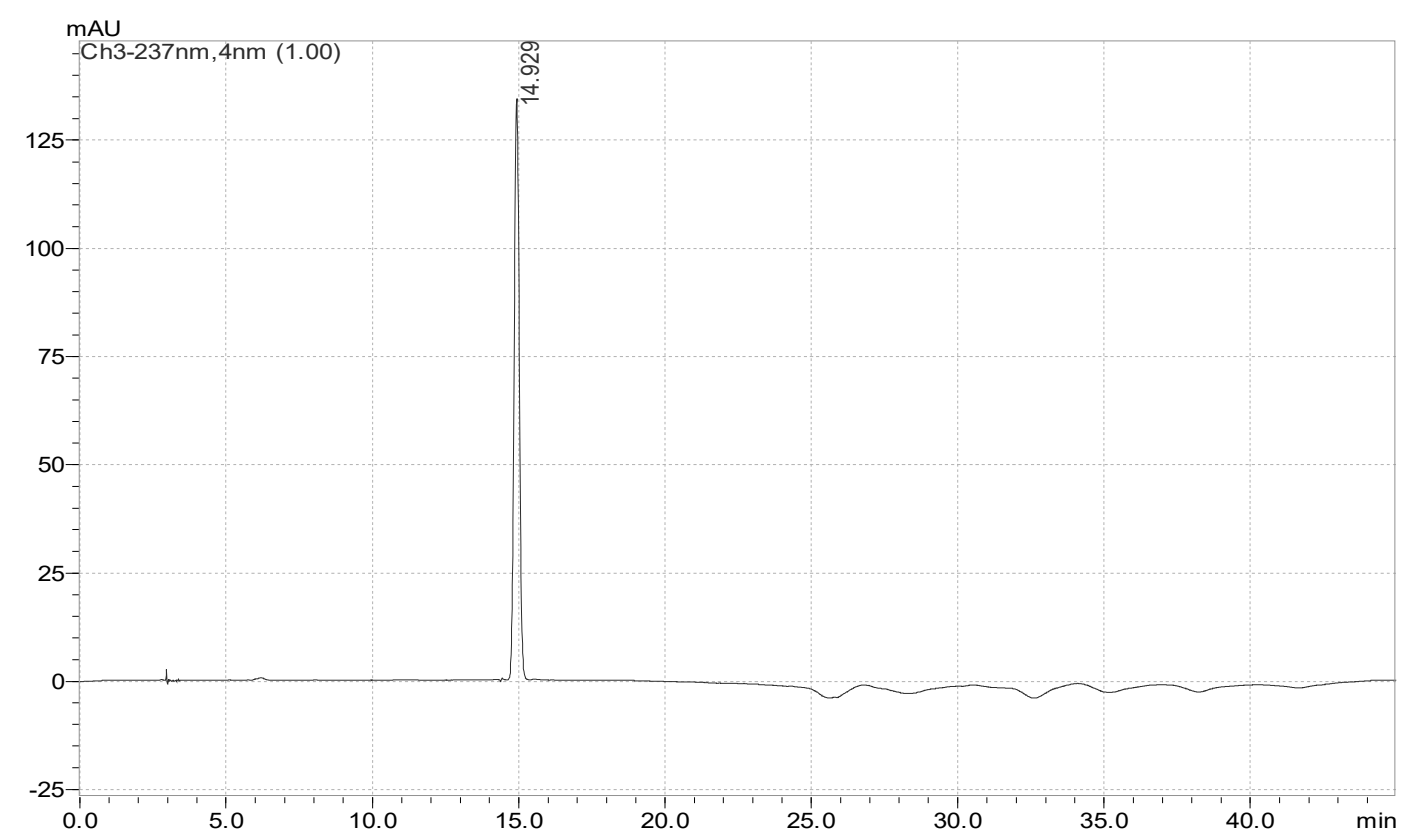

Fig. 2. Chromatogram of a pure sinigrin sample (4.8 $\mathrm{mg}$ in $5 \mathrm{~mL} \mathrm{MeOH} \mathrm{-} \mathrm{80 \% )} \mathrm{-} \mathrm{IPC-A} \mathrm{method} \mathrm{(A=88 \%} \mathrm{in} \mathrm{MeOH}$; $\mathrm{B}=66 \%$ in $\mathrm{MeOH})-1.0 \mathrm{~mL} / \mathrm{min}$

structure, where EN4 grouped similarly with the HPF14 isolate.

The interactions between plantsmicroorganisms and plants-insects are of worldwide importance for agriculture and of increased interest for microbiologists, entomologists and other agriculture professionals. The studies related to plant defense and the interactions with microorganisms and insects were treated until recently as distinct questions; however, in recent years, it has become clear that underlying physiological precursors substantially overlap (35).

The utilization of PGPRs to assist in the pest management was only occasionally observed in the past decade (36), despite reports of the influence of these bacteria as inducing agents of plant resistance against pathogens, which dates to 1911, according to the review by (11).

Although there is little information on the potential of these bacteria, the results obtained in the assay, evaluating the different biological characteristics of the pest fed on the treatments, and indicating the performance of PGPRs in the induction of plant resistance against insects, agree with the points described by (36). In that work, trying to manage bacterial wilt in cucurbits, was observed that inducing resistance elicited by the PGPR isolates, INR-7 of Bacillus pumillus and 90166 of Serratia marcescens, also affected the colonization of the plants by the beetle vectors of the disease, Acalymma vittatum and Diabrotica undecimpunctata. This colonization causes greater reductions in populations when compared to treatments using the chemical insecticide esfenvalerate, and is mostly attributed to a reduction in cucurbitacin production, verified by HPLC analysis (36). Curcubitacin is a triterpenoid of the secondary metabolism in the plant, which is closely related to the food preference of the cited insects. The findings that follow are the most relevant with respect to the action of PGPRs to induce plant resistance against insects.

Also, a decrease of $18 \%$ in female mite Tetranychus cinnabarinus fecundity, in the cucumber cv. 'Corona', was observed when the seeds were treated with Pseudomonas sp., isolate P-112 (9). An increase in the constitutive condition of resistance in the Aramis cultivar still occurs due to the mutualistic association established between the bacteria and the cultivar (9).

\section{Biochemical analysis}

Chromatographs were obtained from the samples subjected to HPLC that demonstrate the diversity of the substances produced by the cabbage plants that were grown in the presence or absence of the PGPR $K$. ascorbata. Among the substances involved in the secondary metabolism of Brassica, sinigrin belongs to the glucosinolate group and is the most cited in the literature; therefore, it is the most understood substance in the biochemical complex of this plant family. Due to the availability of information and the ease of obtaining the substance, which is commercially available as a pure compound, it was used as a comparative standard to analyze the treatment extract as shown in the chromatograph presented in Fig. 2. Sinigrin is known to be involved in the process that stimulates $P$. xylostella feeding (37), by directly acting on the behavior of this pest through antixenosis.

The increment in the quantity produced, the reduction in production or the supplantation of determined substances were shown in Fig. 3. 


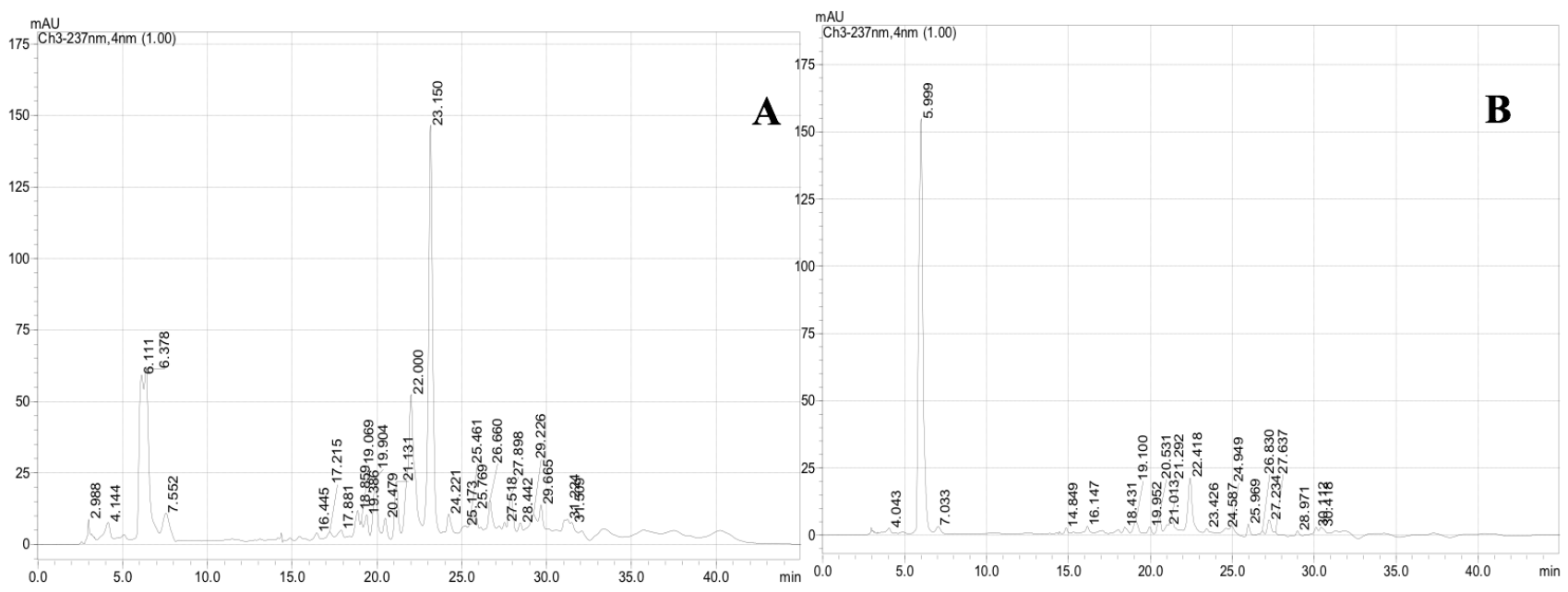

Fig. 3. Chromatogram showing the peaks of the eluted substances: A) extracts of leaves detached from cabbage plants threatened by Plutella xylostella in the greenhouse, grown from non-inoculated seeds; B) extracts of leaves detached from cabbage plants threatened by $P$. xylostella in the greenhouse, grown from seeds inoculated with strain EN4 of Kluyvera ascorbata.

However, new studies are required to identify and quantify these substances.

The measurement of peak intensities for each sample as shown in the graph obtained by the chromatographic method does not identify the compounds; however, it can indicate a pathway to study in future analysis.

In the chromatograms obtained (Fig. 3), treatments can be compared that induced resistance to inoculation with the PGPR $K$. ascorbata in association with leaf injury, caused by $P$. xylostella larval feeding, or just by injury, present a sample of the involved complexity.

The eluted peaks differed among plants grown from seeds that were either inoculated or not inoculated with $K$. ascorbata, which were threatened by the diamondback moth.

In the chromatogram obtained from samples extracted from plants grown from non-inoculated seeds (control), the peak retention times are $\mathrm{RT}=$ 6.111, RT=6.378, $\mathrm{RT}=7.522, \mathrm{RT}=19.386, \mathrm{RT}=$ 20.479, RT= 22.000, RT= 23.150 (Fig. 3A). The chromatogram resulting from seeds incoluated with the $K$. ascorbate, which refers to the best biological result obtained in the bioassay with $P$. xylostella, has differences in intensity among the peaks. For example, RT= 5.999, RT= 14.849 and $\mathrm{RT}=$ 16.147 are highlighted and the intensity of the first peak in the inoculated sample (Fig. 3B) is 2.5 times greater than the non-inoculated sample (Fig. 3A). This fact may suggest a synergistic effect between the stimuli caused by the bacteria and by larval injury.

The biochemical tests were conducted with the intention of obtaining information about the metabolic alterations that occurred in plants when they are exposed to induction factors such as the inoculation of bacteria or injuries caused by insects. Sinigrin was used in this study as the basis of comparison between the visualized metabolic alterations. This could be related to the results obtained earlier by (29), where it was observed that the absence of sinigrin in plants did not alter the resistance response to the diamondback moth, suggesting that these results are consistent with those of (38). He reported that in Brassica, cultivars with low content of the glucosinolates sinigrin and sinalbin, showed no alteration in the susceptibility to Phyllotreta cruciferae and P. xylostella (specific to crucifers), despite noting a five-fold increase in susceptibility of these cultivars to Mamestra configurata (polyphagous insect).

The increase in quantity, reduction or supplanting in the production of determined substances require complementary studies for their identification and quantification. However, metabolic increase was observed only in the plants that were injured by larvae, and a decrease of compounds occurred when the injured plants were inoculated with the PGPR, and these data are similar to the results obtained with the sequencing of the ESTs (expressed sequence tag).

\section{Molecular analysis}

After isolating the genetic material from the cabbage leaf tissue, analysing its integrity and quantifying its concentrations, a cDNA library was constructed of plants attacked by $P$. xylostella larvae, and in only one situation, the cabbage seeds were previously inoculated with $K$. ascorbata. In the library of injured plants, a total of 1,709 clones were obtained. In the plant library, whose seeds had been inoculated with $K$. ascorbata, the number of clones was extremely lower than those obtained from plants that had not been inoculated with a PGPR, leading to the construction of the library in triplicate. Even 

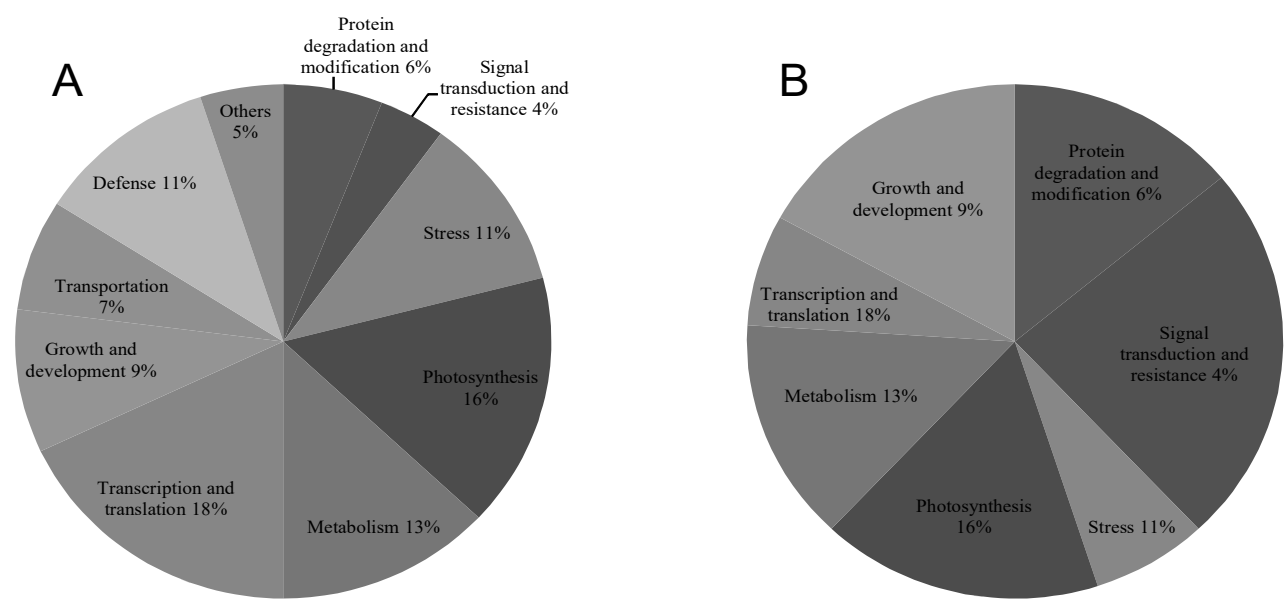

Fig. 4. (A) Percentage of expressed sequence tags (EST) related to cabbage plant metabolism induced by injury from Plutella xylostella. (B) Percentage of ESTs related to cabbage plant metabolism induced by injury from $P$. $x y l o s t e l l a$ and inoculation of strain EN4 of Kluyvera ascorbata.

repeating the construction of this library, only 395 clones were obtained from plants inoculated with the PGPR. The repetition procedure for the library construction was adopted to overcome the possibility of inefficiency in the methodology used. The presence of the $K$. ascorbata bacterium in cabbage plants attacked by $P$. xylostella could alter the metabolism of the plants, which could be attempting to defend themselves against injury.

When the T7 and SP6 oligonucleotide primers were used, it was possible to observe which clones carried the inserted fragment in the vector and, therefore, select them for sequencing analysis. The clones that had strands less than $250 \mathrm{bp}$ (base pairs) were excluded because this size indicates that the vector was inserted into the cell without a cDNA fragment. However, from data generated from the gel electrophoresis, 1,108 clones were selected in the cDNA library of cabbage plants inoculated with $K$. ascorbata and attacked by $P$. xylostella.

By using the BLAST tool, a comparative analysis with genetic sequences was completed and deposited in the National Center for Biotechnology Information (NCBI) website.

The sequences generated and compared with the data available on the site were selected using pre-established criteria, and sequences of greater confidence were selected. The sequences are shown in the supplementary file. Therefore, 376 sequences were selected that are clones from noninoculated plants and 29 sequences were selected that are clones of inoculated plants in which both were injured. These clones had estimated similarity values (e-value $>10)$ between the deposited sequences, and are also compatible with the sequences from the genome of the plant model, A. thaliana. Information on Brassicas is rare, especially for cabbage, which increases the validity and the importance of the information described here, given the pioneering vision of the present study.
With the information concerning the $A$. thaliana genome, the basic functions of each sequence were described. The 376 sequences obtained from the cabbage plants threatened by $P$. xylostella larvae are classified as follows: 42 genes related to plant defense, 23 genes involved in protein degradation or modification, 14 signal transduction genes, 40 stress genes, 59 related to photosynthesis, 49 genes involved in metabolism, 69 with translation and transcription, 35 plant growth and development genes, 28 genes involved in endogenous transport and 17 classified as "other" due to the scarcity of information.

The 29 sequences from cabbage plants that were injured by larvae and were grown from seeds inoculated with the PGPR $K$. ascorbata were classified as follows: 4 sequences refer to genes directly related to plant defense, 7 genes related to stress, 2 genes involved in photosynthesis, 5 genes with metabolism, 4 genes related to the translation and transcription of proteins, 2 genes controlling plant growth and development and 5 related to endogenous transport.

A pie graph of metabolic performance of the plants injured by $P$. xylostella with or without stimuli of induction of resistance by the PGPR $K$. ascorbata was constructed from the sequencing results (Fig. 4).

In the molecular analysis, the cabbage plants that were only threatened by $P$. xylostella larvae, presented about 13 times more ESTs in comparison to the plants that were inoculated with the bacterium $K$. ascorbate, which acted as a resistance inducing agent. Among the validated transcripts, most of the transcripts are related to some plant defense pathways, and they were classified according to the basal function described. However, to determine their exact roles in a specific plant defense pathway, quantification of the protein expression levels will be necessary in future investigations. An enormous discrepancy exists between the number of transcripts in the 
two situations in the study, which was also visualized in the chromatograms (Figs. 2 and 3). This means that when a plant is defending itself against insect infestations, the plant utilizes many mechanisms to survive the injuries caused by the feeding of the pests (39).

The great difference among the quantities of ESTs obtained in the two situations was also observed in the HPLC tests of differences between the metabolites (Fig. 3). This finding can be attributed to the inoculation of the seeds because various previous studies report the molecular and biochemical differentiation among inoculated and non-inoculated plants $(40,41)$. Thus, the increased production of certain compounds over others may be related to a possible increase in the expression of genes related to plant defense, giving the plant the ability to defend itself more precisely. This assumption could be supported by the results of the bioassay carried out in the present study, where the worst biological results were observed for the insects that fed on plants inoculated with the PGPR K. ascorbata.

According to (42), the maintenance of plant defense promotes energy expenditures, and to reduce the energy necessary, plants might use induced defenses to economize energy during the herbivorous attack. In the absence of an induction mechanism, the plant defends itself from herbivores by constitutive mechanisms where most of the energy expenditure is dispensed in defense. However, in the presence of the PGPR, this energy is allocated to plant growth, development and reproduction (Fig. 4A). According to (7), this induced resistance against disease and herbivores, triggered by both biotic and abiotic processes, has much lower metabolic costs because the plant does not undergo large physiological modifications, being highly efficient.

Several metabolic pathways may be accessed by the plants because their defense against insect infestation or infection by pathogens involves basically the same pathways, as a complex network of signals mediated by three main signaling molecules: salicylic acid (SA), ethylene (ET) and jasmonic acid (JA) $(43,44)$. The resistance pathway mediated by SA involves the activation of defense responses at the infection site and systemic responses (SAR) (45). The process occurs by an ion flux through the plasma membrane, followed by the accumulation of superoxide radicals $\left(\mathrm{O}_{2}\right)$ and hydrogen peroxide $\left(\mathrm{H}_{2} \mathrm{O}_{2}\right)$, which are reactive oxygen species (ROS) that interact with nitric oxide and may cause cell death at the infection site (HR - hypersensitivity reaction) (46). In the results obtained by EST sequencing, various genes described in the literature as players in certain metabolic pathways of plant defense were found, as in the case of EST related with ROS (AT1G07890) (47).

The SAR type resistance results in the actuation of elicitors that are involved in the accumulation of PRPs (Proteins Related to Pathogenesis). Their induction is salicylic-dependent and can result in visual alterations such as necrosis of plants that suffered induction, and generally, it is elicited by pathogens, natural substances or synthetic substances (48). Sequences present in this study were also described as PRPs, as is the case of the transcripts AT1G33970, AT5G39730, AT2G38540, AT5G59320, AT5G59310 and AT5G55450, that were encountered in sequences of plants that were not inoculated with $K$. ascorbata.

Some ESTs that may belong to the resistance pathway mediated by SA may have been active in the treatment when the plants were attacked by $P$. xylostella larvae. The appearance of genes related to the difference in the flow of $\mathrm{O}_{2}$ and $\mathrm{Ca}^{2+}$ ions was observed (Supplementary file). For example, calcineurin (AT4G17615), which participates in the calcium signaling pathway and sequences corresponding to avr proteins (AT4G17615, AT5G39730, AT5G13320), hydrogen ion transport (AT4G00895) and calmodulins (AT2G26190, AT4G25800) increased when the plants were injured.

Some cases exist in which gene expression is directly related to the accumulation of SA or it is a response to bacteria, fungi and viruses' infection. However, in the present study, the abiotic factors were controlled so that the plants were maintained in conditions similar to commercial plants (in roofed shelters). Therefore, it can be inferred that most of the genes activated and related to different types of stress, principally those stimulated by abscisic acid, oxidative reductions, SA and JA are related to plant defense against injuries caused by pests.

The suppression or enhancement of biological characteristics of the insects tested in this study's bioassay are likely to have closer relationships with the expression of genes related to the induction of responses to injury, or the formation of glucosinolates and brassinosteroids. Glucosinolates and brassinosteroids are regularly reported as sources of resistance to insect pests of brassicas (49).

The plant defense response against insects is principally regulated by the action of the JA molecule, which is also related to defense against environmental stresses, mechanical injury and phytopathogenic infections $(50,51)$, and some of these responses may also involve the synergistic participation of ET (52). JA is synthesized from linolenic acid, which is liberated from plasma membrane lipids by the octadecanoid pathway (53). Nevertheless, it is possibly recognized and transduced by currently unidentified receptors. Various ESTs had high homology with genes that participated in the formation pathway of JA or ET, suggesting that some of the genes described in this work are not involved in plant defense against insects. However, they may be involved but are 
not yet recognized as playing a role in the defense against insects.

The appearance of the same gene can be observed in both situations, as is the case with Cytochrome p450 (Supplementary file). This gene is part of a large family of monooxygenases involved in the synthesis of various secondary metabolites including hormones, sterols, fatty acids and plant allelochemicals (54). The enzymes of the Cytochrome p450 family are capable of hydrolysing fatty acids, and these enzymes are involved in the plant response to abiotic stress as well as stress by insects and pathogens (55). Nevertheless, the quantification of expression levels of this gene would be necessary, as with others that repeat in both situations, to establish the gene's influence on the different situations evaluated in this study.

The roles of the genes cited in the present study suggest potential pathways involved in defense and more detailed studies of these pathways are necessary to gain information on their roles in defense.

Given the results obtained with the molecular and biochemical studies, little information is found in the literature, regarding the chemical constitution and alterations that occur due to the variation of stimuli such as infection by microorganisms and/or damage caused by insects.

There are various possibilities and pathways indicated in these tests that suggest that continued verifications of substances and their intensities and the search for their function are necessary. Specifically, the substances that undergo the most alterations need to be studied to uncover the characteristics of induced defense by PGPR in Brassica plants. Such defense systems suggest that traditional improvement techniques such as crossbreeding or more modern techniques such as the insertion of genes that code for such characteristics could be utilized.

Nonetheless, numerous clarifications are still necessary regarding the genetic sequences, which have not yet been paired. Furthermore, the metabolic pathways and protein formation involved in the defense against insects have not yet been studied.

\section{Author's Contributions}

PCBC carried out the molecular analysis. RTT carried out the agricultural and biological analysis, co-supervised the first author and supervised the third author. FHIF organized the manuscript and performed the statistical analysis. AMGT carried out the microbiological analysis and obtained the rhizobacteria strains. MVFL participated in the design of the study and supervised the first author. SAB participated in the design of the study and supervised the second author. All authors read and approved the final manuscript.

\section{Acknowledgements}

We would like to thank FAPESP for supporting this project and Dr. Clara B. Hoffmann- Campo for the biochemical analysis. We also would like to thank the anonymous reviewers for their careful reading and constructive comments.

\section{Competing Interest}

The authors declare that they have no competing interests.

\section{References}

1. Dickson $M$ H, Shelton A M, Eigenbrode S D, Vamosy M L, Mora M. Selection for resistance to diamondback moth (Plutella xylostella) in cabbage. Hort Sci. 1990;25:1643-6.

2. Lin J, Dickson M H, Eckenrode C J. Resistance of Brassica lines to the diamondback moth (Lepidoptera: Yponomeutidae) in the field, and inheritance of resistance. J Econ Entomol. 1984;77:293- 6. doi: doi.org/10.1093/jee/77.5.1293

3. Lin J, Eckenrode E J, Dickson M H. Variation in Brassica oleracea resistance to diamondback moth (Lepidoptera: Plutellidae). J Econ Entomol. 1983;76:1423-7.

doi: doi.org/10.1093/jee/76.6.1423

4. Eigenbrode S D, Shelton A M, Dickson M H. Two types of resistance to the diamondback moth (Lepidoptera: Plutellidae) in cabbage. Environ Entomol. 1990;19:1086-90. doi: doi.org/10.1093/ee/19.4.1086

5. Ulmer B, Gillott C, Woods D, Erlandson M. Diamondback moth, Plutella xylostella (L.), feeding and oviposition preferences on glossy and waxy Brassica rapa (L.) lines. Crop Prot. 2002;21:327-31. doi: doi.org/10.1016/S02612194(02)00014-5

6. Raymond B, Federici B A. In defence of Bacillus thuringiensis, the safest and most successful microbial insecticide available to humanity-a response to EFSA. FEMS Microbiol Ecol. 2017;93(7):1-8. doi.org/10.1093/femsec/fix084

7. Vallad G E, Goodman R M. Systemic acquired resistance and induced systemic resistance in conventional agriculture. Crop Sci. 2004;44:1920-34.

doi: doi.org/10.2135/cropsci2004.1920

8. Hallmann J, Quadt-Hallmann A, Mahafee W F, Kloepper J W. Bacterial endophytes in agricultural crops. Can J Microbiol. 1997;43:895914. doi: doi.org/10.1139/m97-131

9. Tomczyk A. The use of plant growth-promoting rhizobacteria (PGPR) to decrease the susceptibility of cucumber to spider mites. IOBC Bul. 1999;22:251-4.

10. Mariano R L R, Romeiro R S. Indução de resistência sistêmica mediada por rizobactérias promotoras de crescimento de plantas. Controle Biológico: EMBRAPA; 2000. p. 305 -24.

11. Romeiro R S. PGPR e indução de resistência sistêmica em plantas a patógenos. Summa Phytopathol. 2000;26:177-84.

12. Sturz A V, Nowak J. Endophytic communities of rhizobacteria and the strategies required to create yield enhancing associations with crops. 
Appl Soil Ecol. 2000;15:183-90. doi: doi.org/10.1016/S0929-1393(00)00094-9

13. Annapurna $\mathrm{K}$, Kumar A, Kumar LV, Govindasamy V, Bose P, Ramadoss D. PGPRinduced systemic resistance (ISR) in plant disease management. Bacteria in Agrobiology: Disease Management: Springer; 2013. p. 405-25.

14. Thuler $\mathrm{R} \mathrm{T}$, Barros R, Mariano $\mathrm{R} \mathrm{L} \mathrm{R}$, Vendramim J D. Efeito de bactérias promotoras do crescimento de plantas (BPCP) no desenvolvimento de Plutella xylostella (L.) (Lepidoptera: Plutellidae) em couve. Científica. 2006;2:217-22.

15. Walling L L. The myriad plant responses. J Plant Growth Reg. 2000;19:195-216.

16. Kessler A, Baldwin I T. Pant responses to insect herbivory: The emerging molecular analysis. Annu Rev Plant Biol. 2002;53:299-328. doi: doi.org/10.1146/annurev.arplant.53.100301.1352 07

17. Agrios G N. Plant Pathology. 5th eds. Department of Plant Pathology University of Florida United States of America. 2005.

18. Durrant W E, Dong $X$. Systemic acquired resistance. Annu Rev Phytopathol. 2004;42:185209.

doi:

doi.org/10.1146/annurev.phyto.42.040803.140421

19. Van Loon L C, Bakker P A H M, Pieterse C M J. Systemic resistance induced by rhizosphere bacteria. Annu Rev Phytopathol. 1998;36:453-83. doi: doi.org/10.1146/annurev.phyto.36.1.453

20. Cattelan A. Métodos qualitativos para determinação de características bioquímicas e fisiológicas associadas com bactérias promotoras do crescimento vegetal: Embrapa Soja; 1999.

21. Mariano R L R, Kloepper J W. Método alternativo de biocontrole: resistência sistêmica induzida por rizobactérias. Rev An Patol Plantas. 2000;8:121-37.

22. Germida J, De Freitas J, editors. Growth promotion of cabbage, lettuce and onion by fluorescent pseudomonads under growth chamber conditions. Improving plant productivity with rhizosphere bacteria Proceedings of the Third International Workshop on Plant Growth-Promoting Rhizobacteria CSIRO Division of Soils, Adelaide, S Australia; 1994.

23. Turner J T, Backman $\mathrm{P}$ A. Factors relating to peanut yield increases after seed treatment with Bacillus subtilis. Plant Dis. 1991;75:347-53. doi: doi.org/10.1094/PD-75-0347

24. Lazarovits G, Nowak J. Rhizobacteria for improvement of plant growth and establishment. HortScience. 1997;32: 188-192.

25. Van Wees S C, Luijendijk M, Smoorenburg I, Van Loon L C, Pieterse C M. Rhizobacteria-mediated induced systemic resistance (ISR) in Arabidopsis is not associated with a direct effect on expression of known defense-related genes but stimulates the expression of the jasmonateinducible gene Atvsp upon challenge. Plant Molec Biol. 1999;41:537-49. doi: doi.org/10.1023/A:1006319216982

26. Mariano R, Assis S, Silveira E. Preservação de bactérias fitopatogênicas. Mariano, RLR \& Silveira, EB (Coords) Manual de Práticas em Fitobacteriologia 2a ed Recife UFRPE. 2005:3545.
27. Tukey J W. Section of mathematics and engineering: some selected quick and easy methods of statistical analysis. New York Acad Sci. 1953;16:88-97. doi: doi.org/10.1111/j.21640947.1953.tb01326.x

28. Sneath P H, Sokal R R. Numerical taxonomy. The principles and practice of numerical classification. 1973.

29. Thuler R T, De Bortoli S A, Hoffmann-Campo C B. Classificação de cultivares de brássicas com relação à resistência à traça-das-crucíferas e à presença de glucosinolatos. Pesqui Agropecu Bras. 2007;42:467-74. doi: doi.org/10.1590/S0100204X2007000400003

30. Betz J, Fox W. High-performance liquid chromatographic determination of glucosinolates in Brassica vegetables. ACS Publications; 1994.

31. Sambrook J, Russel D W. Molecular Cloning: A Laboratory Manual: Cold Spring Harbor Laboratory Press; 2001.

32. Hanahan D. Studies on transformation of Escherichia coli with plasmids. J Mol Biol. 1983;166:557-80. doi: doi.org/10.1016/S00222836(83)80284-8

33. Tamura K, Dudley J, Nei M, Kumar S. MEGA4: Molecular Evolutionary Genetics Analysis (MEGA) software version 4.0. Mol Biol Evol. 2007;24:1596-9.

doi: doi.org/10.1093/molbev/msm092

34. Altschul S F, Madden T L, Schäffer A A, Zhang J, Zhang Z, Miller W, Lipman D J. Gapped BLAST and PSI-BLAST: a new generation of protein database search programs. Nucleic Acids Res. 1997;25:3389-3402. doi.org/10.1093/nar/25.17.3389

35. Koornneef A, Pieterse C M J. Cross-talk in defense signaling. Plant Physiol. 2008;146:83944. doi: doi.org/10.1104/pp.107.112029

36. Zehnder G, Kloepper J, Yao C, Wey G. Induction of systemic resistance in cucumber against cucumber beetles (Coleoptera: Chrysomelidae) by plant growth promoting rhizobacteria. J Econ Entomol. 1997;90:381-96. doi: doi.org/10.1093/jee/90.2.391

37. Thorsteinson A J. The chemotactic influence of plant constituents on feeding by phytophagous insects. Entomol Exp Appl. 1958;1:23-7. doi: doi.org/10.1111/j.1570-7458.1958.tb00005.x

38. Bodnaryk R P. Will low glucosinolate cultivars of the mustards Brassica juncea and Sinapis alba be vulnerable to insect pests? Can J Plant Sci. 1997;77:283-7. doi: doi.org/10.4141/P96-113

39. Mithöfer A, Boland W. Plant defense against herbivores: chemical aspects. Annu Rev Plant Biol. 2012;63:431-50. doi: doi.org/ 10.1146/annurev-arplant-042110-103854

40. Timmusk S, Wagner E G. The plant-growthpromoting rhizobacterium Paenibacillus polymyxa induces changes in Arabidopsis thaliana gene expression: a possible connection between biotic and abiotic stress responses. Mol Plant Microbe Interact. 1999;12:951-9. doi: doi.org/ 10.1094/MPMI.1999.12.11.951

41. Yang J, Kloepper J W, Choong-Min R. Rhizosphere bacteria help plants tolerate abiotic stress. Trends Plant Sci. 2009;14:1-4. doi: doi.org/10.1016/j.tplants.2008.10.004 
42. Agrawal A. Plant defense: signal in insect eggs. Tree, 2000;9:357. doi: doi.org/10.1016/s01695347(00)01943-1

43. Clarke J D, Volko S M, Ledford H, Ausubel F M, Dong X. Roles of salicylic acid, jasmonic acid and ethylene in cpr-induced resistance in Arabdopsis. Plant Cell 2000;12:2175-90. doi: doi.org/10.1105/tpc.12.11.2175

44. Ton J, Van Pelt J A, Van Loon L C, Pieterse C M. Differential effectiveness of salicylate and jamonate/ethylene-dependent induced resistance in Arabidopsis. Molec Plant Microbe In. 2002;15: 27-34. doi: doi.org/10.1094/MPMI.2002.15.1.27

45. Ryals J A, Neuenschwander U H, Willits M G, Molina A, Steiner H Y, Hunt M D. Systemic acquired resistance. Plant Cell. 1996;8:1809-19. doi: doi.org/10.1105/tpc.8.10.1809

46. McDowell J M, Dangl J L. Signal in the plant immune response. Trends Biochem Sci. 2000;25:79-82. doi: doi.org/10.1016/S09680004(99)01532-7

47. Apel K, Hirt H. Reactive Oxygen Species: metabolism, oxidative stress, and signal transduction. Annu Rev Plant Biol. 2004;55:373$99 . \quad$ doi: doi.org/ 10.1146/annurev.arplant.55.031903.141701

48. Sticher L, Mauch-Mani B, Metraux J P. Systemic acquired resistance. Annu Rev Phytopathol. 1997;35: 235-70. doi: doi.org/10.1146/annurev.phyto.35.1.235

49. Mithen R. Glucosinolates - biochemistry, genetics and biological activity. Plant Growth Regul. 2001;34:91-103. doi: doi.org/ 10.1023/A:1013330819778
50. McConn M, Creelaman R A, Bell E, Mullet F E, Browse J. Jasmonate is essential for insect defense in Arabidopsis. PNAS. 1997;94:5473-7. doi: doi.org/10.1073/pnas.94.10.5473

51. Overmyer K, Tuominen H, Kettunen R, Betz C, Langebartels C, Sandermann H, Kangasjarvi J. Ozone-sensitive Arabidospsis rcd1 mutant reveals opposite roles for ethylene and jasmonate signaling pathways in regulating superoxide-dependent cell death. Plant Cell. 2000;12:1849-62. doi.org/10.1105/tpc.12.10.1849

52. Guo H, Ecker J R. The ethylene signaling pathway: new insights. Curr Opin Plant Biol. 2004;7: 40-9. doi: doi.org/10.1016/j.pbi.2003.11.011

53. Taiz L, Zeiger E. Fisiologia vegetal:Artmed; 2009.

54. Smigocki A C, Wilson D. Pest and disease resistance enhanced by heterologous suppression of a Nicotiana plumbaginifolia cytochrome P450 gene CYP72A2. Biotechnol Lett. 2004;26: 1809-1814. doi: doi.org/10.1007/s10529-004-4615-8

55. Kandel S, Morant M, Benveniste I, Blee E, Werck-Reichhart D, Pinot F. Cloning, functional expression, and characterization of CYP709C1, the first sub-terminal hydroxylase of long chain fatty acid in plants. Induction by chemicals and methyl jasmonate. J Biol Chem. 2005;280:35881-9. doi.org/10.1074/jbc.M500918200 doi: 